\title{
Saúde e política na crise da Covid-19: apontamentos sobre a pandemia na imprensa brasileira
}

\author{
Health and politics in the Covid-19 crisis: notes on the pandemic in the \\ Brazilian press
}

\section{Salud y política en la crisis de Covid-19: notas sobre la pandemia en la prensa brasileña}

\author{
Luiz Marcelo Robalinho Ferraz ${ }^{1, a}$ \\ marcelo.robalinho@ichca.ufal.br | https://orcid.org/oooo-0002-6861-3626 \\ ${ }^{1}$ Universidade Federal de Alagoas, Instituto de Ciências Humanas, Comunicação e Arte. Maceió, AL, Brasil. \\ a Doutorado em Informação e Comunicação em Saúde pela Fundação Oswaldo Cruz.
}

\section{Resumo}

Nunca a saúde e a política pareceram estar tão relacionadas como nesta pandemia da Covid-19. Tomando como exemplo o noticiário do jornal Folha de S.Paulo entre janeiro e maio de 2020, analisamos as características que singularizam a cobertura da imprensa brasileira sobre essa síndrome respiratória recémdescoberta. O avanço da doença e o anúncio da pandemia pela Organização Mundial de Saúde levaram a uma superexposição do assunto nos meios de comunicação, chegando a um limite na produção jornalística, de março até a primeira quinzena de abril. Isso ocorreu antes de se verificar o aumento na curva de casos. Depois, a crise política deflagrada com a pandemia provocou uma redução gradativa das publicações, até o fim de maio, contrapondo-se à subida de casos, em um período de agravamento da doença.

Palavras-chave: Coronavírus; Covid-19; Epidemiologia; Folha de S.Paulo; Jornalismo; Pandemia.

\begin{abstract}
Health and politics appear closely related in the COVID-19 pandemic, more than ever. Taking as an example the news from the Brazilian newspaper Folha de S.Paulo from January to May 2020, we analyze the characteristics that differentiate the press coverage about this newly discovered severe acute respiratory syndrome in Brazil. The progress of the disease and the announcement of the pandemic by the World Health Organization, on March 11, led to an overexposure of the subject in the media, reaching a limit in journalistic production, from March until the first half of April. This occurred even before an increase in the curve of COVID-19 cases in Brazil. Later on, the political crisis caused a gradual reduction in publications, until the end of May, opposing the rise in cases, in a period of worsening disease.
\end{abstract}

Keywords: Coronavirus; Covid-19; Epidemiology; Folha de S.Paulo; Journalism; Pandemic. 


\section{Resumen}

Nunca antes la salud y la política parecían estar tan estrechamente relacionadas como en esta pandemia de Covid-19. Tomando como ejemplo las noticias del periódico brasileño Folha de S.Paulo entre enero y mayo de 2020, analizamos las características que hacen que la cobertura de la prensa de este síndrome respiratorio agudo severo recientemente descubierto sea única en Brasil. El avance de la enfermedad y el anuncio de la pandemia por parte de la Organización Mundial de la Salud, el 11 de marzo, condujeron a una sobreexposición del tema en los medios, llegando a un límite en la producción periodística, de marzo hasta la primera quincena de abril. Esto ocurrió incluso antes de que hubiera un aumento en la curva de casos en Brasil. Posteriormente, la crisis política desencadenada por la pandemia provocó una reducción gradual de las publicaciones, hasta finales de mayo, oponiéndose al aumento de los casos, en un período de agravación de la enfermedad.

Palabras clave: Coronavirus; Covid-19; Epidemiología; Folha de S.Paulo; Pandemia; Periodismo.

\section{Introdução}

O ano de 2020 entrará como um período singular da nossa História, em função da crise sanitária provocada pela pandemia da Covid-19 em curso. Houve impactos diretos em diversos setores, devido aos desdobramentos decorrentes da nova doença em diversos países, e no Brasil em especial. Partindo do registro inicial de casos de uma pneumonia ainda sem nome e de causa desconhecida na província de Wuhan, na China, por autoridades de saúde em 31 de dezembro de $2019^{1}$, vimos a doença ser nomeada pela mídia primeiro como novo coronavírus e depois identificada por Covid-19 (termo que hoje conhecemos), junto com o vírus causador, o SARS-CoV-2.

O que parecia ser uma síndrome respiratória distante se tornou uma realidade sentida mais de perto por cidadãos de várias partes do planeta, com sobrecarga nos sistemas de saúde e adoção de práticas sanitárias (isolamento, distanciamento social, quarentena ou bloqueio total). Nesse cenário, os relatos jornalísticos foram decisivos para dar 'vida' à Covid-19, devido a uma publicação diária sem precedentes por parte dos meios de comunicação. No país, porém, na contramão do agravamento das tendências epidemiológicas, a crise política suscitada pela pandemia ganhou contornos particulares, com a disputa entre atores públicos dos três poderes, o Executivo em especial. Situação que contribuiu posteriormente para a redução da cobertura sobre o assunto, como veremos neste artigo.

\section{A causalidade na convergência entre jornalismo e epidemiologia}

A divulgação de informações sobre doenças costuma ter forte apelo, devido ao risco que representam para a vida das pessoas. Isso se exacerba nas epidemias. Como acontecimentos singulares no ambiente social e no universo discursivo ${ }^{2-3}$, os eventos epidêmicos se inserem no contexto das calamidades públicas por se tratar de doenças transmissíveis. Em 2009, a gripe A (H1N1), a popular suína, converteu-se na potencial ameaça sanitária do século XXI, trazendo de volta a memória da gripe espanhola, da gripe asiática e da gripe aviária no noticiário. Foi encarada como uma doença de grandes proporções, sobretudo com o anúncio da pandemia pela Organização Mundial de Saúde (OMS) ${ }^{4}$ e transformou-se em acontecimento jornalístico, sendo os enunciados determinantes para a midiatização dessa gripe.

Bastante explorada pela mídia, a ideia de causalidade é importante para a compreensão que temos sobre as doenças, as infectocontagiosas em especial. Dita a experiência de adoecimento, determinando a origem 
da enfermidade a um agente patogênico externo (vírus e bactérias, por exemplo). No caso das doenças não transmissíveis, a causalidade se une ao fator de risco para indicar as chances de um indivíduo vir a adoecer, sobretudo através dos discursos jornalísticos, que disseminam em larga escala ideia(s) de saúde e doença para a população.

Termo caro ao pensamento científico, a causalidade integra o conjunto das bases epistemológicas da epidemiologia, sendo útil na construção dos procedimentos de mensuração de saúde das populações5. Ligado a uma lógica cartesiana, é um princípio que busca valorizar a evidência do método. Para explicar a ocorrência das doenças ou de outros eventos ligados à saúde, a categoria de causalidade contribui para pensar e calcular as estimativas com o apoio da estatística.

Da parte do jornalismo, a ideia de causalidade também pode ser observada no fazer cotidiano dos órgãos da imprensa, só que em outro contexto. No contrato de comunicação midiático ${ }^{6}$, o processo de transformação pelo qual passa o acontecimento já na fase de produção da notícia o insere em uma lógica causal a fim de poder ser organizado e interpretado. Acontecimentos sanitários, como as epidemias, passam por um processo de construção semântica, em que são articulados outros elementos na narrativa jornalística, como as razões, os responsáveis, as implicações de determinado fato na vida social e os possíveis desdobramentos.

Nas pandemias, o contexto de imprevisibilidade que as caracteriza também representa, em termos jornalísticos, um atributo importante para a noticiabilidade ${ }^{7}$ de um acontecimento epidemiológico dessa natureza. Mais que uma epidemia, que já carrega em si uma forte carga simbólica, falar de pandemia nos remete à desordem causada pelo caráter acidental da doença em larga escala na população mundial, provocando mortes e afetando a rotina de cidades, estados e países.

Por isso, ela adquire um sentido particular no cotidiano das sociedades, a partir do momento em que se enfatiza discursivamente o 'fantasma' do perigo e do descontrole que uma doença simboliza no espaço geográfico e no dia a dia das pessoas. Torna-se notícia também pelo peso social (atinge a população em geral), pela quantidade de envolvidos (mortos, infectados e potenciais doentes), pela proximidade geográfica (evento sanitário planetário e relação com território noticiado) e pela atualidade (evento do momento), levando-se em conta outros critérios de noticiabilidade7.

No caso da Covid-19 e da gripe A (H1N1), a imprensa noticiou mais do que outras doenças pela novidade do assunto, a partir do registro da pandemia. Em geral, os eventos epidêmicos costumam ter uma atenção especial pelo impacto sobre a sociedade e o risco de morte, aspectos valorizados nas primeiras páginas. Com a Covid-19, a produção jornalística apresentou um crescimento muito significativo. Embora o distanciamento entre pessoas para evitar o contágio fosse um procedimento secular, a ocorrência, pela primeira vez, de uma quarentena de proporções globais foi um fator decisivo para diferenciar o noticiário sobre essa síndrome respiratória ${ }^{8}$.

\section{A cobertura da Covid-19 na Folha de S.Paulo}

Na imprensa brasileira, o jornal paulista Folha de S.Paulo, periódico de maior circulação no país na atualidade ${ }^{9}$, publicou 13.404 textos jornalísticos tratando da Covid-19 como assunto principal ou secundário nos primeiros cinco meses de 2020, considerando a versão impressa e outros formatos disponíveis na versão digitali . Nos veículos tradicionais, a Covid-19 está presente em praticamente todas as editorias, de política à nacional, passando por economia, esportes e cultura, cada qual com abordagens e enquadramentos diversos. O desenrolar dos fatos, com a divulgação diária de novos casos e mortes, além da superlotação nas UTIs e dos estudos científicos em torno da nova doença, foi fundamental para a superexposição sem precedentes da Covid-19 no noticiário.

i Levantamento feito pelo autor no sistema de busca do periódico para este artigo. Disponível em: https://www.folha.uol.com.brl. 
Isso fica claro quando relacionamos o quantitativo de publicações com o acumulado de casos confirmados. É o que se vê no diagrama midialógico da Covid-19 (Figura 1), representação gráfica que compara a produção semanal do jornal sobre a infecção respiratória (colunas azuis) com a curva da doença (linha vermelha). Trata-se de um instrumento de monitoramento que ajuda a analisar a evolução da cobertura jornalística em paralelo à evolução dos registros epidemiológicos no Brasil ${ }^{10-11}$. Neste paper, consideramos a contabilização de textos e casos por semana epidemiológicaii, em função das características de vigilância da Covid-19 no mundo $o^{\mathrm{iii}}$.

Pela Figura 1, a produção da Folha oscilou entre 4 e 254 publicações entre as semanas epidemiológicas 4 (19 a 25 de janeiro) e 10 (1 a 7 de março). Nesse período, o noticiário esteve voltado, sobretudo, à descoberta do vírus desconhecido e às mortes, na China, à chegada da doença na Europa, ao registro dos primeiros casos suspeitos e das confirmações no Brasil, à declaração da OMS da situação como emergência de saúde pública de preocupação internacional diante do surto global, em 30 de janeiro e, então, aos preparativos do país face à ameaça cada vez mais próxima.

A constatação da transmissão local da Covid-19 em São Paulo e o registro de casos no Nordeste deram margem a um aumento gradativo de textos no jornal, em função da proximidade da síndrome respiratória entre os brasileiros. Aspectos que, associados à confirmação da pandemia, no dia 11 de março ${ }^{12}$, culminaram com o registro de 741 publicações na semana epidemiológica 11 ( 8 a 14 de março). O pico na produção, em números absolutos, na Folha de S.Paulo ocorreu logo em seguida na semana epidemiológica 12 (15 a 21 de março) com o registro de 1.437 textos.

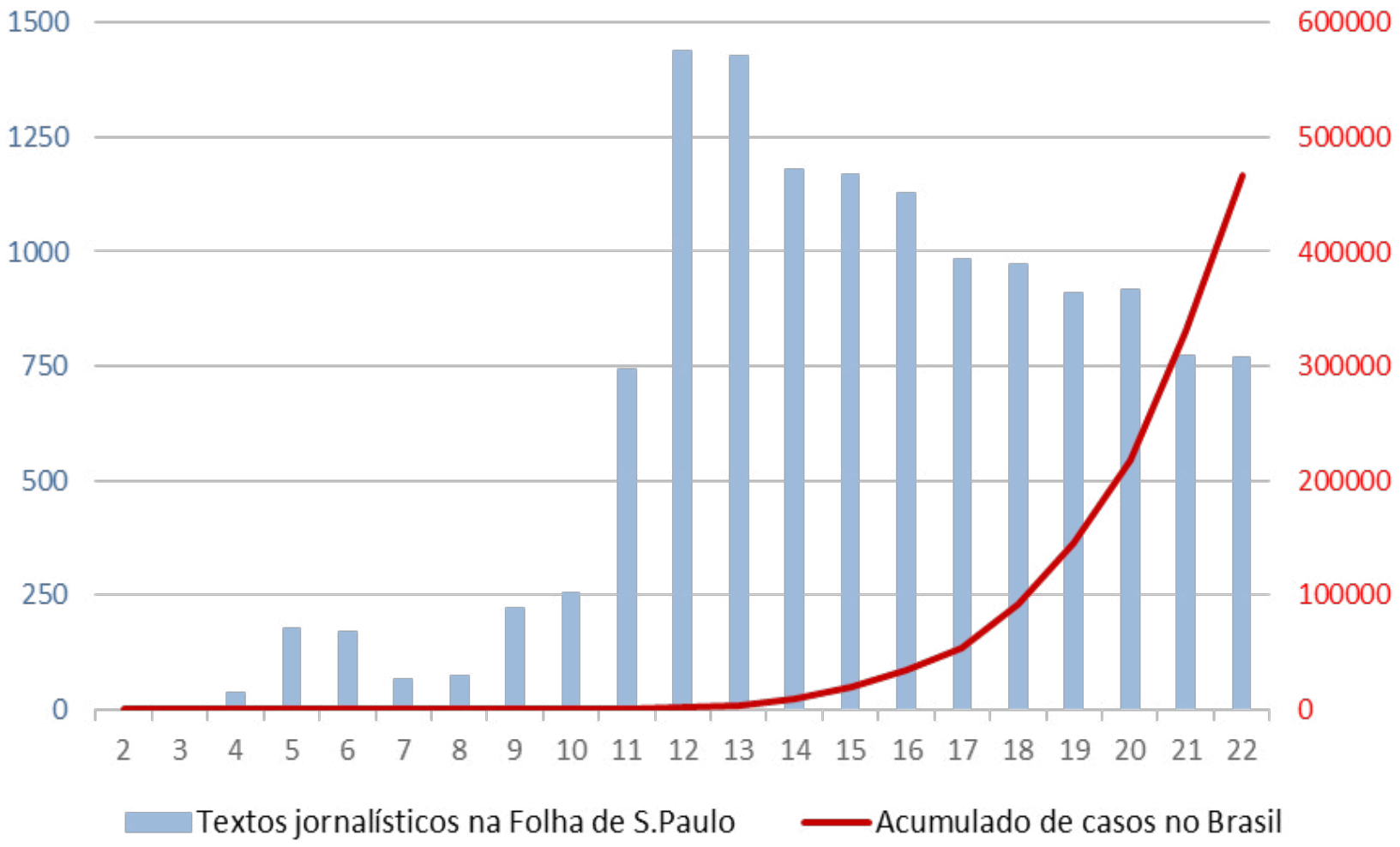

Figura 1 - Diagrama midialógico da Covid-19, Folha de S.Paulo, 2020 Fonte: O autor (2020).

Nessa fase, a Covid-19 ocupou o espaço do noticiário por inteiro, incluindo as capas, sendo o principal foco de quase todas as manchetes e chamadas diárias. Esse foi um dos diferenciais da cobertura em relação

ii Semana epidemiológica é uma padronização internacional usada para notificação de doenças e agravos de notificação compulsória. Por convenção, conta-se sempre de domingo a sábado.

iii Os registros da Covid-19 foram coletados no banco de dados do Centro Europeu de Prevenção e Controle de Doenças (ECDC). Disponível em: https://bit.ly/3h0U3zq. 
a epidemias anteriores noticiadas. Afora as medidas de prevenção e controle anunciadas pelas autoridades, incluindo as restrições econômicas e a liberação de recursos para ajudar a população trabalhadora afetada, a minimização da doença por parte do Presidente da República, Jair Bolsonaro, e as consequentes críticas de políticos e protestos da população foram destaque no noticiário, trazendo à tona a crise política, algo que se exacerbou posteriormente.

Observando atentamente ao gráfico, percebemos uma contraposição curiosa entre notícias e casos. Embora a Folha estivesse bastante atenta à situação do novo coronavírus no país e no mundo, a evolução dos textos publicados pelo jornal não acompanhou, de forma concomitante, a evolução da doença no país, cuja subida ocorreu, duas semanas depois, no período de 29 de março a 4 de abril (semana epidemiológica 14), momento em que a curva começou a crescer.

O decréscimo do noticiário nesse período já indicava que a produção da Folha havia atingido um pico, apontando que as publicações tinham chegado a um máximo entre as semanas 12 e 13 e depois passado por um processo de queda quase regular da semana 14 em diante. A situação se confirmou, a partir de então, quando o total de notícias foi decaindo paulatinamente até chegar à marca dos 768 textos na última semana analisada (24 a 30 de maio). Ou seja, a produção jornalística esteve bem mais intensa e declinou antes mesmo de a crise sanitária brasileira se agravar.

A nosso ver, essa queda se deveu a dois fatores. Um deles, já mencionado, foi a crise política do nosso país, bastante explorada a partir da segunda quinzena de abril, quando a pandemia foi perdendo espaço para polêmicas e desentendimentos entre o Presidente da República e atores políticos de diferentes esferas de governo. O outro, mais sistêmico, disse respeito ao processo de saturação informativa, devido à superexposição do tema no próprio jornal, levando a cobertura noticiosa ao máximo e depois a uma redução gradativa, pelo próprio contexto político.

\section{Um fim possível?}

As cenas dos próximos capítulos desta 'intriga' em torno da Covid-19 nós não sabemos. Em andamento, a narrativa jornalística ainda terá um longo desenrolar nos próximos meses, principalmente no estágio de crescimento e estabilização da curva de casos no Brasil. Ela deverá se estender provavelmente até 2021, em função do avanço da nova doença nas periferias das grandes cidades e no interior do país. Os acontecimentos vivenciados em escala global por populações de várias partes do planeta - e relatados por meio da imprensa - já nos revelam um 'novo normal' pós-Covid.

Novos padrões de consumo, novas formas de interação social (mais distância e menos toques entre pessoas), educação a distância, expansão do home office como forma de trabalho e transmissões on-line de espetáculos artísticos são alguns exemplos. A compreensão que temos da Covid-19 como ameaça natural externa (risco social exógeno) afetando as sociedades revela muito da vulnerabilidade e do potencial descontrole de uma pandemia em um mundo cada vez mais vigiado e controlado.

Por outro lado, essa mesma fragilidade traz à tona questões importantes, como a responsabilidade compartilhada, a solidariedade global e a ação urgente para os mais necessitados, na busca por um caminho mais sustentável e justo para todos, diferentemente do "antigo normal"13. Questões a serem abordadas, em maior ou menor grau, pelos órgãos da imprensa, a depender do contexto epidemiológico e dos interesses ideológicos e econômicos em jogo pelos governos. Por ora, a grande expectativa é o desenrolar da crise política e o fim da pandemia em curso. E, é claro, a tão sonhada vacina capaz de imunizar a todos nós da ação do vírus, fato que levará meses para ser notícia. Até lá, muita água correrá por debaixo desta ponte... 


\section{Referências}

1. World Health Organization, Emergencies preparedness, response, Disease Outbreak News (DONs). Pneumonia of unknown cause, China. Genève: The Organization; 2020 Jan. 05 [cited 2020 May 28]. Available from: https://www.who.int/csr/don/05-january-2020-pneumonia-of-unkown-cause-china/en/.

2. Foucault M. A arqueologia do saber. 7. ed. Rio de Janeiro: Forense; 2007.

3. Foucault M. O nascimento da clínica. 6. ed. Rio de Janeiro: Forense; 2006.

4. Gomes IMAM, Ferraz LMR. Ameaça e controle da gripe A(H1N1): uma análise discursiva de Veja, Istoé e Época. Saúde Soc [Internet] 2012 abr./jun. [citado em 2020 maio 29];21(2):302-13. Disponível em: https://bit.ly/3cB3RNh.

5. Almeida Filho N, Castiel LD, Ayres JR. Risco: conceito básico da epidemiologia. In: Barreto ML, Almeida Filho N, organizadores. Epidemiologia e saúde: fundamentos, métodos e aplicações. São Paulo: Guanabara Koogan; 2011. p. 43-54.

6. $\quad$ Charaudeau P. Discurso das mídias. São Paulo: Contexto; 2006.

7. Silva G. Para pensar critérios de noticiabilidade. In: Silva G, Silva MP, Fernandes ML, organizadores. Critérios de noticiabilidade: problemas conceituais e aplicações. Florianópolis: Insular; 2014. p. 51-69.

8. Quarentena global é evento inédito na história das pandemias. Agência Brasil (EBC). 202026 abr. [citado 1 jun. 2020]:Saúde. Disponível em: https://bit.ly/3eSEFDn.

9. Folha cresce e lidera circulação entre jornais do país em 2019. Folha de S.Paulo (Grupo Folha). 202021 jan. [citado em 2020 maio 31]. Disponível em: https://bit.ly/2Ufra8Y.

10. Ferraz LMR. Epidemia e memória: narrativas jornalísticas na construção discursiva sobre a dengue [dissertação]. Recife: Universidade Federal de Pernambuco; 2010.

11. Ferraz LMR, Gomes IMAM. A construção discursiva sobre a dengue na mídia. Rev Bras Epidemiol [Internet]. 2012 mar. [citado em 2020 jun. 01];15(1):63-74. Disponível em: https://bit.ly/3720rCa.

12. Coronavirus disease 2019 (COVID-19): situation report - 51 [Internet]. Genève: World Health Organization; 202011 March [cited 2020 May 31]. 9 p. Situation Report - 51. Available from: https://bit. ly/2Y2ZWUI.

13. A UN framework for the immediate socio-economic response to COVID-19. New Yourk: United Nations; 2020 Apr. [cited 2020 June 01]. Available from: https://bit.ly/3eSzjrW. 